Supplement of Solid Earth, 11, 1597-1615, 2020

https://doi.org/10.5194/se-11-1597-2020-supplement

(c) Author(s) 2020. This work is distributed under

the Creative Commons Attribution 4.0 License.

(c) (i)

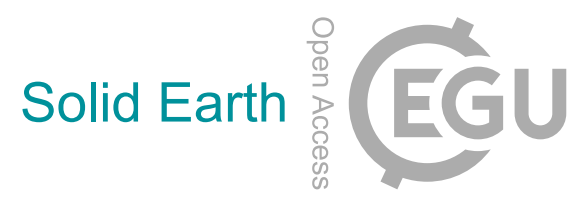

Supplement of

\title{
Introducing noisi: a Python tool for ambient noise cross-correlation modeling and noise source inversion
}

Laura Ermert et al.

Correspondence to: Laura Ermert (lermert@fas.harvard.edu)

The copyright of individual parts of the supplement might differ from the CC BY 4.0 License. 


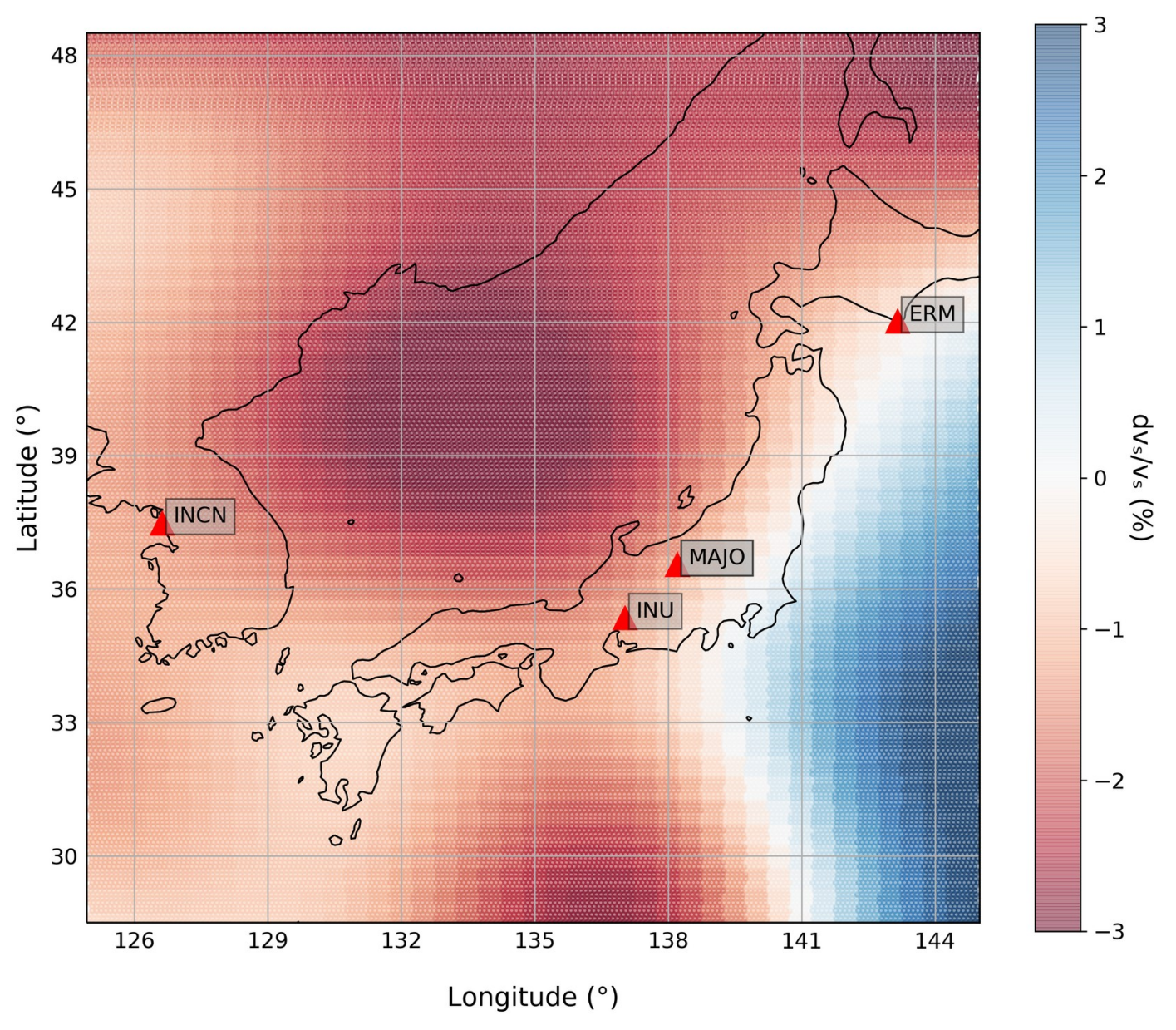

Figure S1: Model domain, seismic stations, and velocity model used in the comparison with SPECFEM3D_globe. Red triangles show the stations. Color map shows the deviation of S40RTS shear wave velocity from PREM. S40RTS velocity perturbations were obtained from SubMachine (https://www.earth.ox.ac.uk/ smachine/cgi/index.php), see Hosseini et al. (2018). 

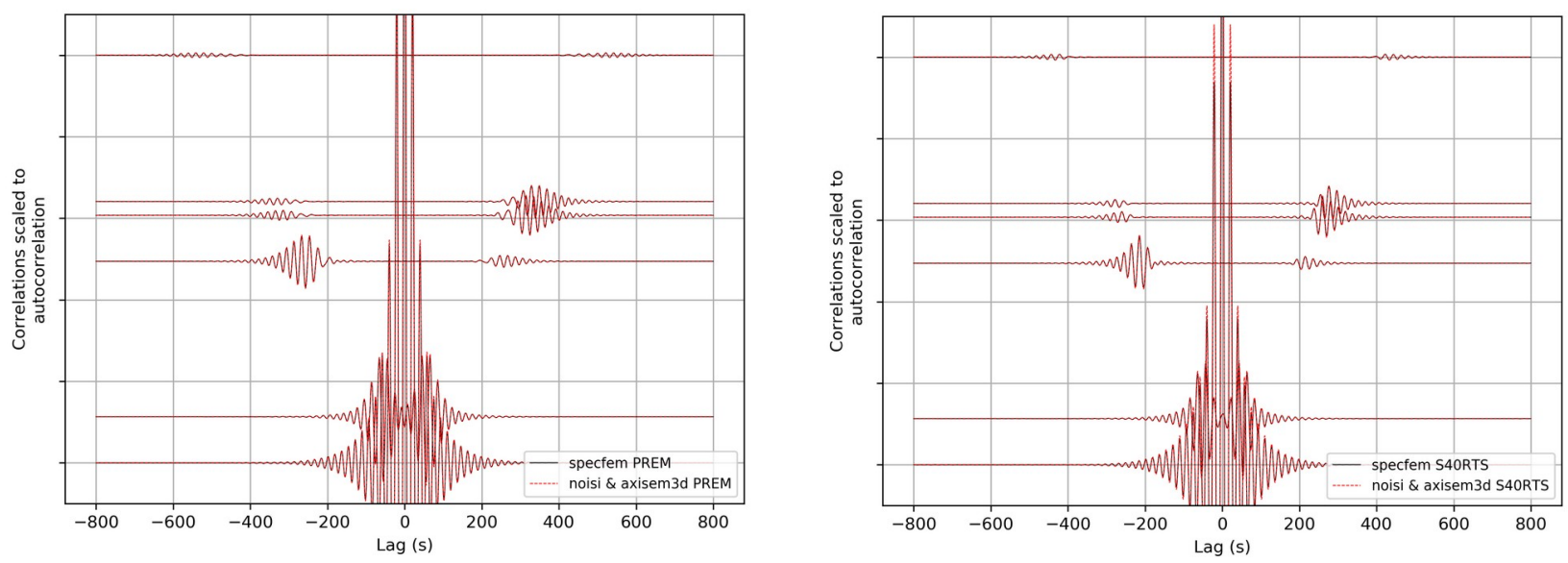

Figure S2: Showing the correlation traces shown in Figure 2 of the main manuscript, but here with a common amplitude normalization (preserving relative amplitude).
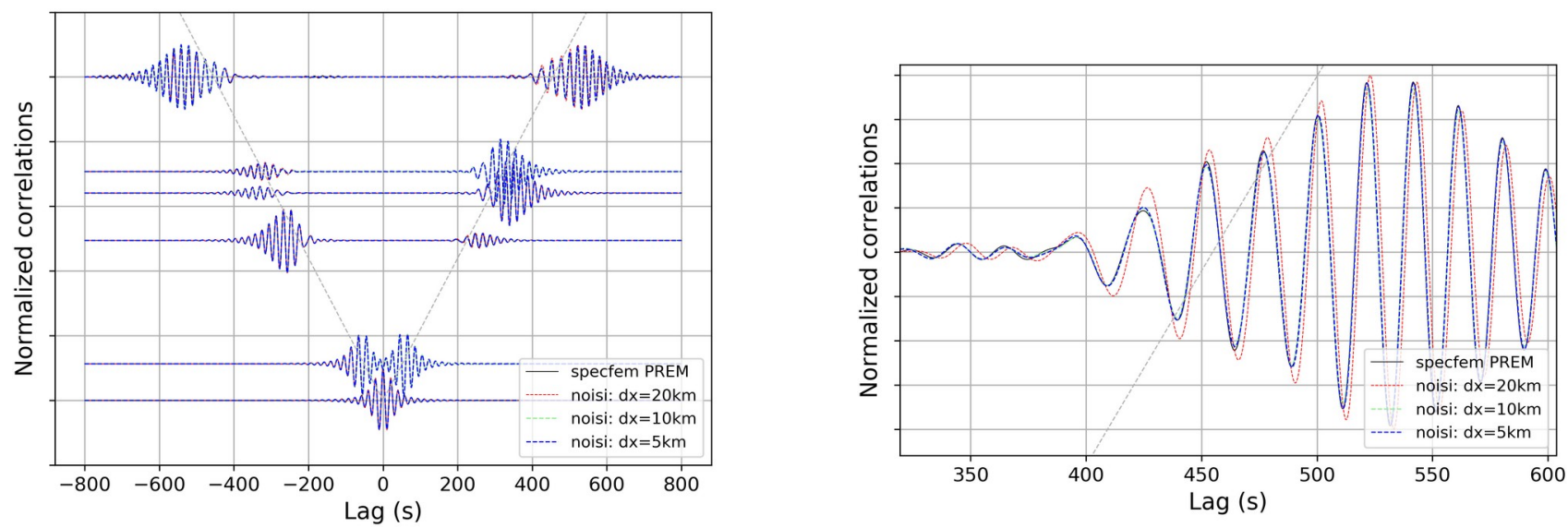

Figure S3: Influence of the grid step, i.e. the integral discretization, on the outcome. The grid step used for the comparison in Figure 2 of the main manuscript is $10 \mathrm{~km}$. The fit with SPECFEM3D_globe can be improved by using a $5 \mathrm{~km}$ grid step. However, a $10 \mathrm{~km}$ grid step produces an accuracy that is probably satisfactory for most applications, while a coarser step of $20 \mathrm{~km}$ clearly degrades the result. 